\title{
eCommons@AKU
}

Department of Surgery

July 2007

\section{Recurrent pineal apoplexy in a child}

Kashif Majeed

Aga Khan University

S. Ather Enam

Agha Khan University, ather.enam@aku.edu

Follow this and additional works at: http://ecommons.aku.edu/pakistan_fhs_mc_surg_surg Part of the Surgery Commons

\section{Recommended Citation}

Majeed, K., Enam, S. (2007). Recurrent pineal apoplexy in a child. Neurology, 69(1), 112-114.

Available at: http://ecommons.aku.edu/pakistan_fhs_mc_surg_surg/188 


\section{Clinical/Scientific Notes}

Christian A. Helland, MD

Knut Wester, MD, PhD
MONOZYGOTIC TWINS WITH MIRROR IMAGE CYSTS: INDICATION OF A GENETIC MECHANISM IN ARACHNOID CYSTS?

Arachnoid cysts are benign, congenital malformations of the arachnoid. The mechanism of cystogenesis remains unclear.

In other diseases with cysts in various organs as a hallmark of the disease, such as autosomal dominant polycystic kidney disease (ADPKD), a genetic basis for the disease has been described. ${ }^{1}$ In ADPKD, arachnoid cysts have been reported to co-exist. $^{2}$

The observations of familial occurrence of arachnoid cysts, ${ }^{2,3}$ in combination with the observed co-existence of arachnoid cysts and genetically determined cystic diseases, ${ }^{2,3}$ indicate a genetic component in the cystogenesis of at least some of the arachnoid cysts.

In this article, we present the first report of mirror image arachnoid cysts in the cerebellopontine angle in a pair of monozygotic twins and discuss the implications this might have for a possible genetic component in the development of arachnoid cysts.

Case report. These 12-year-old twins were born by vaginal delivery at 40 weeks' gestation after the uneventful pregnancy of a healthy 24-year-old mother. Both had Apgar score 9/9 at 1 and 9/9 at 5 minutes. The placenta was examined and described as monochorionic. Twin 1 was slightly smaller than Twin 2: weight 2,900 and 3,370 g, length 50 and $51 \mathrm{~cm}$, and head circumference 34 and $34 \mathrm{~cm}$, respectively.

Twin 1 was examined by a physiotherapist owing to a tendency of rotating her head to the right during the first three months of life.

The two sisters have had a normal psychomotor development and did not differ much in their early achievements. They are now attending seventh grade in the Norwegian school system, normal for their age.

One of the twins (Twin 1) was referred for neurosurgical evaluation owing to a severe headache following a minor head trauma without loss of consciousness (playing soccer). An initial CT scan was normal, with the exception of an arachnoid cyst in the right cerebellopontine angle. This observation was later verified by MRI (figure, A and $\mathrm{B}$ ). The headache remained intense for several weeks, and she was therefore operated with extirpation and fenestration of the cyst without complications. An MRI of her twin sister revealed a mirror image arachnoid cyst in the left cerebellopontine angle (figure, C and D).

Discussion. Twin studies are often used to determine the genetic component in various diseases, with the basic assumption that monozygotic twins are genetically identical and hence that concordance is indicative of a genetic component of the disease. Previous twin studies on brain structure have demonstrated a highly heritable component in cerebral and hemispheric volumes, ${ }^{4}$ but a structural-functional variation in brain structure in monozygotic twins has also been described. ${ }^{5}$ This variation can also be in the form of mirror imaging, ${ }^{6}$ a chirality that might result from enantiomer information in the very early mammalian embryo.?

For some locations, arachnoid cysts have been reported to have a familial occurrence, either as an isolated entity, or in covariation with other diseases., ${ }^{2,3}$

In our total surgical material of patients with arachnoid cysts $(\mathrm{n}=299)$, only $5.4 \%$ of the cysts are located in the cerebellopontine angle. The rarity of this location makes it very unlikely that this cooccurrence in a pair of monozygotic twins had arisen by chance.

The association of arachnoid cysts with other diseases where a genetic basis of cystogenesis have been discovered and the current finding of mirror imaging of arachnoid cysts in the cerebellopontine angle in monozygotic twins indicate that, for at least some cysts, the cystogenesis may have a genetic component.

From the Section for Neurosurgery, Department of Surgical Sciences, University of Bergen, and Department of Neurosurgery, Haukeland University Hospital, Bergen, Norway.

Disclosure: The authors report no conflicts of interest.

Received November 21, 2006. Accepted in final form February 7, 2007.

Address correspondence and reprint requests to Dr. C.A. Helland, Department of Neurosurgery, Haukeland University Hospital, N-5021Bergen, Norway; chhe@helse-bergen.no

Copyright (C) 2007 by AAN Enterprises, Inc. 
(A and B) Coronal and axial MR images of symptomatic twin with an arachnoid cyst of the right cerebellopontine angle. (C and D) Coronal and axial MR images of asymptomatic sister with an arachnoid cyst of the left cerebellopontine angle

Figure MRI of the twins

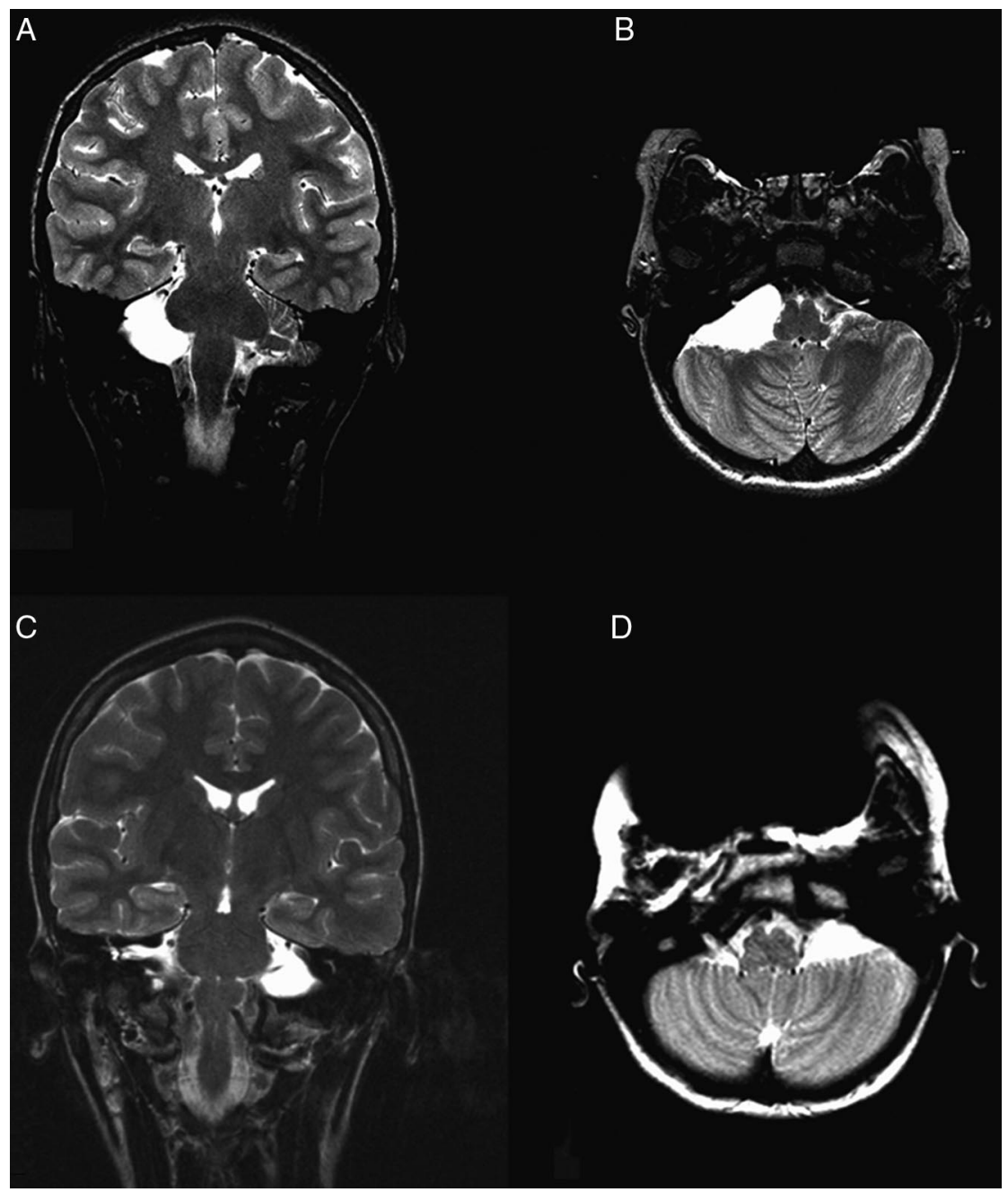

1. Lee JE, Park MH, Park JH. The gene expression profile of cyst epithelial cells in autosomal dominant polycystic kidney disease patients. J Biochem Mol Biol 2004;37:612617.

2. Alehan FK, Gurakan B, Agildere M. Familial arachnoid cysts in association with autosomal dominant polycystic kidney disease. Pediatrics 2002;110:e13.

3. Orlacchio A, Gaudiello F, Totaro A, et al. A new SPG4 mutation in a variant form of spastic paraplegia with congenital arachnoid cysts. Neurology 2004;62:1875-1878.
4. Bartley AJ, Jones DW, Weinberger DR. Genetic variability of human brain size and cortical gyral patterns. Brain 1997;120:257-269.

5. Sommer IE, Ramsey NF, Mandl RC, Kahn RS. Language lateralization in monozygotic twin pairs concordant and discordant for handedness. Brain 2002;125:2710-2718.

6. Sommer IE, Ramsey NF, Bouma A, Kahn RS. Cerebral mirrorimaging in a monozygotic twin. Lancet 1999;354:1445-1446.

7. Levin M. Twinning and embryonic left-right asymmetry. Laterality 1999;4:197-208.
John Hardy, PhD

Andrew Singleton, PhD
REPORTING AND INTERPRETATION OF GENETIC VARIANTS IN CASES AND CONTROLS When a new gene for a disease is reported, of course, the investigators in every lab with DNA samples relevant to that finding go to their freezers and get out their samples and begins to sequence that gene. Typically, they screen control series for those variants they find, but do not sequence their control samples. Whereas these studies are straightforward, their definitive interpretation is often problematic, especially in cases where mutations may not be fully penetrant. An excellent proven example of this is the recent identification of a clearly pathogenic progranulin mutation in case of ubiquitin-positive frontal dementia in which a presenilin variant had been previously described ${ }^{1}$; and an earlier example was the realization that the presenilin $1 \mathrm{E} 318 \mathrm{Y}$ was a harmless polymorphism and not disease causing. ${ }^{2}$

When performing this type of screening study or reading a manuscript that describes this approach, there are some straightforward considerations. 
First, strictly, the pathogenicity of each individual mutation (especially missense changes) should be proven by either of the two standard genetic tests: segregation or association. Some changes may be rare variants or private polymorphisms (occurring only in a single family), which, though they may not be found by the authors in large numbers of controls, are nevertheless not pathogenic.

Second, the interpretation of the occurrence of mutations in samples labeled as controls is often not straightforward: Volunteers for genetic studies are often family members, and inexperienced collection of such samples can lead to misleading data. In addition, sample labeling is subject to human error at appreciable rates, and if a finding is unexpected, it should ideally be checked by resampling.

Third, especially in recessive diseases, where there is loss of function, nongeneticists need to be aware that there are many mutation types that can be difficult to identify (such as deletions). Identification of individuals with single mutations in such cases is very problematic. A recent example of this is the unresolved debate on the pathogenicity of single parkin mutations. ${ }^{3}$

Although these are simple rules, they are often difficult to follow in practice. Family structures are usually not ideal for genetic analysis, and resampling can be problematic for practical and ethical reasons. Ideally, a large number of controls from several ethnic backgrounds should be sequenced rather than the common practice of screening for mutation occurrence in a single ethnic background. However, this is often too expensive or arduous to be practical. When these strictures have not been followed, authors should explain why they were not, so that the scientific community can have a true value of their clinical worth: Caveat lector! Authors must discuss the realistic possibilities relating to their finding, without a bias toward the most attractive option (usually one of causality). ${ }^{4}$ Likewise, editors of all journals must recognize the value of clarity in reporting these types of finding: While pathogenicity is a more saleable entity, it can mislead a field for many years and result in wasted time and resources.

From the Laboratory of Neurogenetics, National Institute on Aging, Bethesda, MD.

Disclosure: The authors report no conflicts of interest.

Received October 16, 2006. Accepted in final form February 12, 2007.

Address correspondence and reprint requests to Dr. J. Hardy, Laboratory of Neurogenetics, National Institute on Aging, NIH, Bldg. 10, Rm. 6C103, Bethesda, MD 20892; hardyj@mail.nih.gov

Copyright (C) 2007 by AAN Enterprises, Inc.

1. Boeve BF, Baker M, Dickson DW, et al. Frontotemporal dementia and parkinsonism associated with the IVS1+1 $\mathrm{G} \rightarrow$ A mutation in progranulin: a clinicopathologic study. Brain 2006;129:3103-3114.

2. Mattila KM, Forsell C, Pirttila T, et al. The Glu318Gly mutation of the presenilin-1 gene does not necessarily cause Alzheimer's disease. Ann Neurol 1998;44:965-967.

3. Kay DM, Moran D, Moses L, et al. Heterozygous parkin point mutations are as common in control subjects as in Parkinson's patients. Ann Neurol 2006; [Epub ahead of print]

4. Lehmann-Horn F. Disease-causing mutations or functional polymorphisms? Acta Myol 2004;23:85-89.
Kashif Majeed, MD

S. Ather Enam, MD, $\mathrm{PhD}$

\section{RECURRENT PINEAL APOPLEXY IN A CHILD}

Pineal apoplexy denotes sudden hemorrhage occurring into the pineal gland or a cyst or a mass in pineal region. In clinical neuroscience, pituitary apoplexy is a well established entity. Hemorrhage into a pineal gland is, however, extremely uncommon. The first case of pineal apoplexy was reported in 1976 following use of anticoagulation medications. ${ }^{1}$ Since then, 12 cases have been described in the literature (table). ${ }^{2}$ Repeated bleeding into the pineal gland has been considered a possible risk, but no such case has been reported previously. ${ }^{3}$

Surgical intervention is usually recommended for pineal apoplexy; however, conservative management has also been tried. ${ }^{2}$ Acute hydrocephalus that may result in pineal apoplexy can be taken care of by a ventriculoperitoneal (VP) shunt. Hemorrhagic mass into the pineal gland can then be managed expectantly and has been suggested. ${ }^{2}$ However, recurrence of benign apoplexy necessitates surgical evacuation of hematoma to prevent compression of brain stem. In this article, the authors present a case of recurrent pineal apoplexy into a pineal cyst in a child. To the authors' knowledge, this is the first reported case of recurrent pineal apoplexy.

Case report. History and examination. A previously well young girl presented to the emergency room (ER) with worsening headache and vomiting. Two weeks earlier, she had developed neck pain, which gradually turned into diffuse headache. A day before coming to the ER, she had impaired mentation. On presentation she had severe headache followed by six episodes of vomiting. Her general and systemic examination was unremarkable except that she had bilateral horizontal gaze nystagmus and an 


\begin{tabular}{|c|c|c|}
\hline Report & I cases of pineal apoplexy & \\
\hline Case no./age, y/sex & Clinical presentation & Pathology \\
\hline $1 / 56 / \mathrm{M}^{1,7}$ & Acute severe headache, disorientation, eye signs & Pineal cyst \\
\hline $2 a^{*} / 13 / M^{7}$ & Episodic severe headache, sudden death & Pineocytoma \\
\hline $2 b / 18 / F^{7}$ & Episodic severe headache, eye signs later & Pineocytoma \\
\hline $3^{*} / 54 / M^{7}$ & Progressive headache, eye signs, sudden collapse and death & Ganglioglioma \\
\hline $4 / 51 / F^{7}$ & Acute severe headache, loss of consciousness & Pineal cyst \\
\hline $5^{*} / 20 / F^{7}$ & Sudden death & Pineal cyst, AVM \\
\hline $6 / 30 / M^{7}$ & Progressive headache & Pineal cyst \\
\hline $7 / 9 \mathrm{mo} / \mathrm{M}^{7}$ & Sudden onset of vomiting, irritability & Rhabdoid tumor \\
\hline $8 / 35 / F^{7}$ & Episodic headache, sudden collapses, papilledema & Pineal cyst \\
\hline $9 * 7$ & Not spontaneous although reported after Au implant, sudden loss of consciousness, death & Ectopic pinealoma \\
\hline $10 / 58 / F^{7}$ & Worsening following VP shunt, drowsiness, eye signs & Pineocytoma \\
\hline $11^{+} / 71 / F^{2}$ & Drowsiness, vomiting, headache, unsteadiness & Pineal cyst \\
\hline $12 / 11 / F^{3}$ & Headache, lethargy & Cavernous angioma \\
\hline $13^{\ddagger} / 10 / F$ & Worsening headache, impaired concentration, and gaze paresis & Pineal cyst ${ }^{\ddagger}$ \\
\hline
\end{tabular}

upward gaze paresis. She was conscious, alert, and oriented. Her routine laboratory investigations were all normal.

Imaging. MRI scan revealed a well defined nonenhancing mass in the posterior half of the third ventricle measuring $2.3 \times 2.7 \mathrm{~cm}$. It was hyperintense on T1- and hypointense on T2-weighted images (figure 1). The lesion was pressing onto the tectal plate, obstructing CSF flow leading to hydrocephalus.

Course of disease. A VP shunt was inserted. Her CSF examination and levels of human chorionic gonadotrophin and $\alpha$-fetoprotein were normal. Her symptoms improved subsequently. A CT scan obtained before discharge revealed mixed hypo- and hyperdense signals depicting a resolving subacute hemorrhage (figure 2A).

She presented again with neck pain after 5 days. On her second day of admission, she became very drowsy and irritable and developed an upward gaze paresis. CT scan was consistent with recurrent hemorrhage into a pineal cyst (figure 2B).

Surgery and postoperative course. She underwent suboccipital craniotomy for excision of cyst and evacuation of hematoma. The diagnosis of pineal cyst was confirmed on histopathologic examination of the specimen. Her postoperative course was uneventful. Her immediate postoperative CT scan and a follow-up MRI scan 3 months later did not reveal any residual or recurrent lesion in the pineal region. The child was normal neurologically. She went back to school and adjusted well.

Discussion. Symptomatic pineal apoplexy is extremely rare. Only four cases have occurred in the pediatric population, and none of them had recurrence (table). The hematoma recurred in this case while she was still under conservative care.
Sagittal T1-weighted image (A) and axial contrastenhanced Tl-weighted image (B) show hyperintense lesion without any contrast enhancement. The lesion shows low attenuation on T2weighted images (C).

\section{Figure $1 \quad$ MRI scans of pineal apoplexy at presentation}
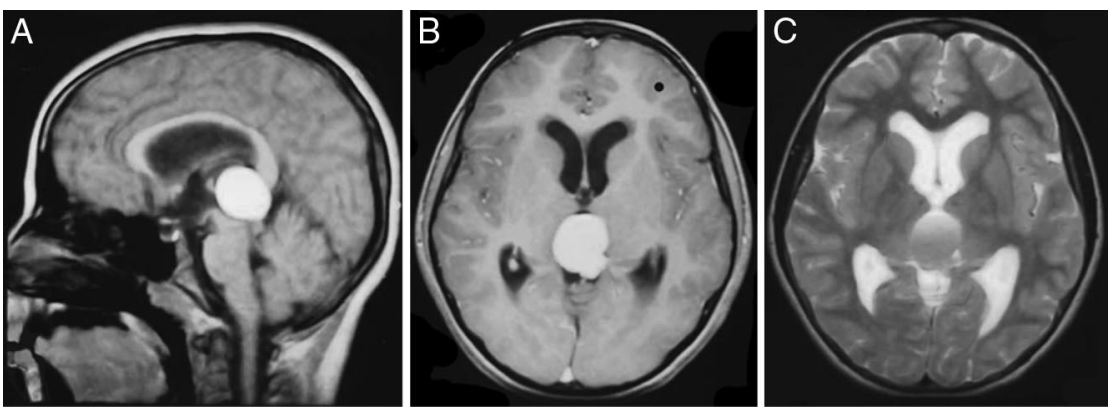
CT scans demonstrating partial resolution of pineal hematoma 13 days after the initial presentation (A) and recurrence of hematoma evident as hyperdense signal in the pineal region 20 days after initial presentation (B)
Figure 2 CT scan on recurrent pineal apoplexy on follow-up
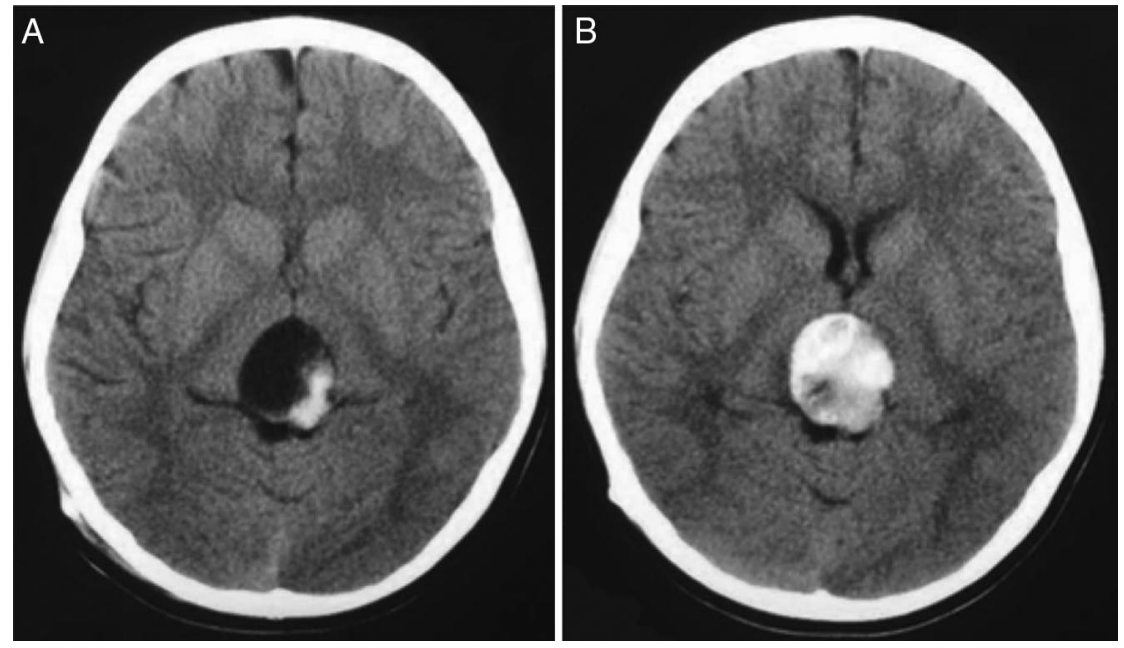

Apart from pineal cysts, other pathologies that may precipitate pineal apoplexy are pineal gland tumors and hemorrhage from the adjacent vascular malformations. ${ }^{4,5}$ Spontaneous hemorrhage into the cystic gland parenchyma due to anticoagulation use has also been reported. ${ }^{1}$ The mortality of pineal apoplexy is high; 4 of the 12 reported patients died of massive hemorrhage (table).

Pineal cysts present in three clinically distinct syndromes: paroxysmal headaches with gaze paresis; chronic headache, gaze paresis, papilledema, and hydrocephalus; and pineal apoplexy with acute obstructive hydrocephalus, the most uncommon presentation of a symptomatic pineal cyst. ${ }^{3,6} \mathrm{~Pa}$ tients with symptomatic pineal apoplexy can be categorized into two groups (table): those presenting with rapid deterioration in consciousness and headache and those who present with sudden coma leading to death.

Almost half $(46.1 \%)$ the cases of pineal apoplexy were due to pineal cysts (table). The rest had different precipitating factors. No association was noted between pineal apoplexy and the age of the patient as all four cases in pediatric patients had different underlying lesions. Four of the 13 cases had had sudden death where the diagnosis was confirmed post mortem.

Surgical extirpation is considered mandatory in all cases to prevent the life-threatening hemorrhage which can compress the brainstem, causing death. ${ }^{3}$ Additionally, specimens can be obtained for histopathologic examination because a confirmed diagnosis can prevent unnecessary treatment for a benign lesion.

Conservative management of pineal apoplexy lacks sufficient evidence. Besides, it can recur, as happened in this case. Therefore, we propose that surgery should be performed early to save these patients from the life-threatening hemorrhage.

From the Department of Biological and Biomedical Sciences (K.M.) and Section of Neurosurgery (S.A.E.), Aga Khan University Medical College, Karachi, Pakistan.

Disclosure: The authors report no conflicts of interest.

Received July 4, 2006. Accepted in final form February 12, 2007.

Address correspondence and reprint requests to Dr. S.A. Enam, Department of Surgery, Aga Khan University, Stadium Road, P.O.Box 3500, Karachi 74800, Pakistan; ather.enam@aku.edu

Copyright (C) 2007 by AAN Enterprises, Inc.

1. Apuzzo ML, Davey LM, Manuelidis EE. Pineal apoplexy associated with anticoagulant therapy. Case report. J Neurosurg 1976;45:223-226.

2. Avery GJ, Lind CR, Bok AP. Successful conservative operative management of pineal apoplexy. J Clin Neurosci 2004;11:667-669.

3. Kobayashi S, Kamagata M, Nakamura M, Nakazato Y, Sasaki T. Pineal apoplexy due to massive hemorrhage associated with cavernous angioma: case report. Surg Neurol 2001;55:365-371.

4. Fuller BG, Kapp DS, Cox R. Radiation therapy of pineal region tumors: 25 new cases and a review of 208 previously reported cases. Int J Radiat Oncol Biol Phys 1994; 28:229-245.

5. Herrmann HD, Winkler D, Westphal M. Treatment of tumours of the pineal region and posterior part of the third ventricle. Acta Neurochir (Wien) 1992;116:137-146.

6. Mukherjee KK, Banerji D, Sharma R. Pineal cyst presenting with intracystic and subarachnoid haemorrhage: report of a case and review of the literature. Br J Neurosurg 1999;13:189-192.

7. Swaroop GR, Whittle IR. Pineal apoplexy: an occurrence with no diagnostic clinicopathological features. $\mathrm{Br} J \mathrm{Neu}$ rosurg 1998;12:274-276. 